\title{
Modeling of the effect of tool wear per discharge estimation error on the depth of machined cavities in micro-EDM milling
}

\author{
Puthumana, Govindan; Bissacco, Giuliano; Hansen, Hans Nørgaard
}

Published in:

International Journal of Advanced Manufacturing Technology

Link to article, DOI:

$10.1007 / \mathrm{s} 00170-017-0371-5$

Publication date:

2017

Document Version

Peer reviewed version

Link back to DTU Orbit

Citation (APA):

Puthumana, G., Bissacco, G., \& Hansen, H. N. (2017). Modeling of the effect of tool wear per discharge estimation error on the depth of machined cavities in micro-EDM milling. International Journal of Advanced Manufacturing Technology, 92(9-12), 3253-3264. https://doi.org/10.1007/s00170-017-0371-5

\section{General rights}

Copyright and moral rights for the publications made accessible in the public portal are retained by the authors and/or other copyright owners and it is a condition of accessing publications that users recognise and abide by the legal requirements associated with these rights.

- Users may download and print one copy of any publication from the public portal for the purpose of private study or research.

- You may not further distribute the material or use it for any profit-making activity or commercial gain

- You may freely distribute the URL identifying the publication in the public portal 


\title{
Effect of tool wear per discharge estimation error on the depth of machined cavities in micro-EDM milling
}

\author{
Govindan Puthumana $^{1 *}$, Giuliano Bissacco ${ }^{1}$, Hans Nørgaard Hansen ${ }^{1}$ \\ ${ }^{1}$ Department of Mechanical Engineering, Technical University of Denmark (DTU), Kgs Lyngby \\ 2800, Denmark. \\ *Corresponding author, E-mail: gput@mek.dtu.dk
}

\begin{abstract}
In micro-EDM milling, real time electrode wear compensation based on tool wear per discharge (TWD) estimation permits the direct control of the position of the tool electrode frontal surface. However, TWD estimation errors will cause errors on the tool electrode axial depth. A simulation tool is developed to determine the effects of errors in the initial estimation of TWD and its propagation effect with respect to the error on the depth of the cavity generated. Simulations were applied to micro-EDM milling of a slot of $5000 \mu \mathrm{m}$ length and $50 \mu \mathrm{m}$ depth and validated through slot milling experiments performed on a micro-EDM machine. Simulations and experimental results were found to be in good agreement, showing the effect of errror amplification through the cavity depth.
\end{abstract}

Keywords: EDM, Precision machining, Tool electrode wear, Simulation, Depth error, Error propagation

\section{Introduction}

The material removal from the tool electrode during a discharge in micro-EDM is indicated by the term 'tool electrode wear'. In micro-EDM milling, as the thickness of each layer for machining is very small as compared to the tool electrode diameter, the tool profile stabilizes rapidly. Tool electrode wear is the single most important factor limiting the manufacturing accuracy in microEDM milling [1].

There have been several approaches to quantify and compensate for the tool electrode wear in macro EDM as well as micro EDM processes. Dauw et al. [2] conducted theoretical analysis of the tool electrode wear in die-sinking EDM. Snoyes at. al. [3] attempted to minimize tool electrode 
wear by employing a newly developed adaptive control system. A uniform wear method for milling EDM by employing a layer-by-layer machining strategy was proposed in [4]. Pham et al. [5] developed a model for estimation of volumetric wear ratio in micro-EDM milling process. In another investigation, the wear resistance of different tool electrode materials in micro-EDM process was assessed [6]. An attempt to minimize tool wear by applying novel materials characterized by high thermal conductivity and high melting point was reported in [7]. Bleys et al. [8] developed a method that combines anticipated wear compensation and real time wear sensing for milling EDM. Another approach has been to measure the discharge energy and to correlate it with the real time compensation [9]. Li et al. [10] developed a new technique where the area scanned by the tool electrode is evaluated in order to apply a continuous compensation along the toolpath. Narasimhan et al. [11] developed a model for generation of tool paths in macro and micro EDM processes. The anticipated tool electrode wear compensation using a sophisticated CAM software was developed and demonstrated [12]. Jung et al. [13] have applied real time tool wear compensation based on pulse frequency control and monitoring of discharge pulses. Zhang et al. [14] have developed a simulation tool for fixed length compensation in micro-EDM milling process. Wang et al. [15] proposed a method to analyse a reverse current flow in micro-EDM process during the counting and monitoring of pulses in order to reduce the tool electrode wear.

Recently, a novel approach has been developed based on discharge counting and statistical characterization of discharge population [16]. This method is based on the assumption that machining occurs by means of trains of discharges with identical distribution as that of the entire discharge population. Thus, in such an approach, the tool wear compensation is performed based on direct monitoring of the tool electrode frontal surface in real time. The method has shown the potential to be effectively used for machining of free form geometries by micro-EDM milling. However, error in the initial estimation of the Tool Wear per Discharge (TWD) affect the accuracy of the machined geometries.

Initial TWD estimation error in fact generates depth errors which are cumulated at each machining layer. Furthermore, determination of the correct TWD using the existing methods is challenging. Therefore, this paper investigates the effect of TWD estimation error on cavity depth through simulations and experimental validation. The paper is organized into four sections. In section 2, discharge characterization for determination of trigger level to count discharges for tool wear compensation is presented. Section 3 briefly discusses simulations of machined surface 
profiles with TWD estimation errors. Section 4 presents the simulation of the effect of propagation of TWD error on machined surface profile at different cavity depths and a simulation of the effect of material removal per discharge (MRD) error on the depth error. In section 5, a method for determination of correct TWD using the simulation tool developed by the authors is described, followed by experimental validation and conclusions.

\section{Discharge characterization}

The electrode wear compensation based on TWD in micro-EDM milling is done based on a correlation between the TWD and average discharge energy obtained using a population of discharges measured during the machining process. Therefore, based on this procedure, the discharge population has been characterized in this work.

In order to determine the trigger level for counting discharges to calculate the tool wear compensation length, discharge population is to be characterized. To characterize the discharges during a $\mu \mathrm{EDM}$ milling process, it is necessary to measure and assess the electric current and voltage that are delivered to the workpiece and tool during machining. For this purpose, a current probe and a voltage probe are used. In this work, the current signals are evaluated for the purpose of discharge population characterization. A Pearson current monitor model 6585 with a bandwidth of $200 \mathrm{MHz}$ is used to measure the current signals, and to further characterize the population of the current signals. A Rohde \& Schwarz RTO1014 oscilloscope is used to acquire the current waveforms. The oscilloscope was programmed remotely through a LAN connection by a Matlab script on an external computer. A schematic diagram for the experimental procedure is shown in Fig. 1. 


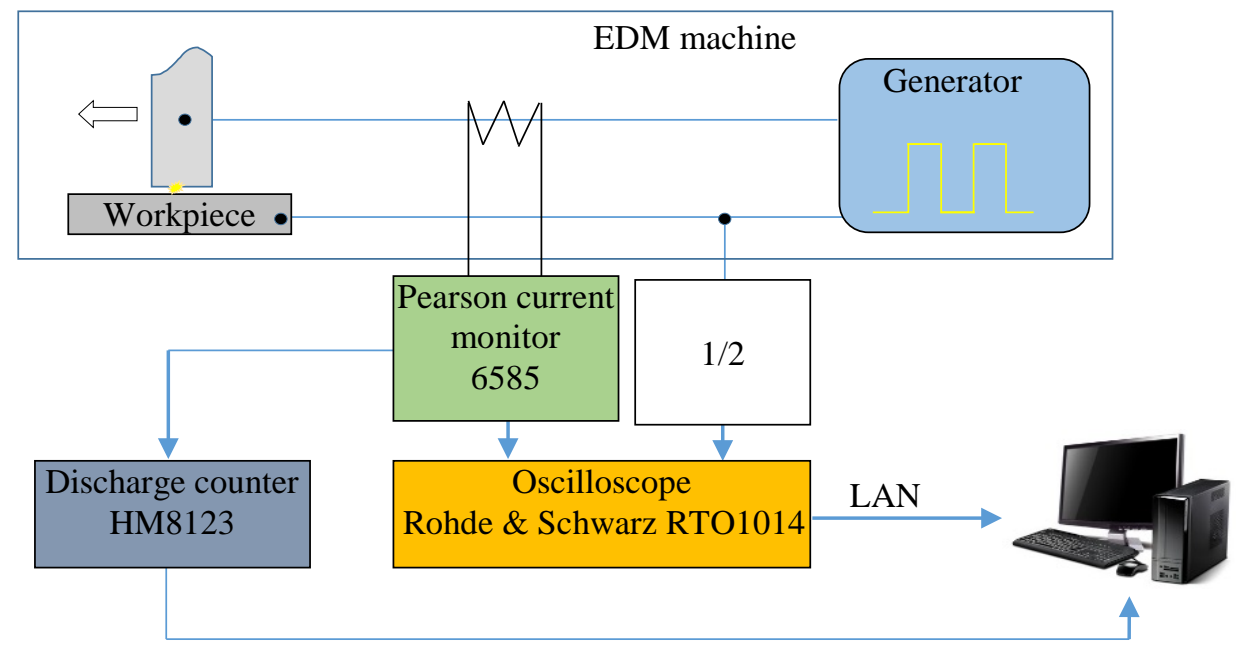

Fig. 1 A schematic diagram for the experimental procedure

Experiments at energy index of 105 were performed on a SARIX SX-200 micro-EDM milling machine to acquire and characterize the discharges (current signals) in order to depict the discharge population. Tungsten carbide rod of nominal $\varnothing 300 \mu \mathrm{m}$ and stavax martensitic steel blocks were used as the tool and workpiece respectively. The test feature that has been selected for machining experiments is a circular pocket having a diameter of about $1000 \mu \mathrm{m}$ and a depth of about $100 \mu \mathrm{m}$. The tool path was prepared using a standard G-code. The machining is carried out layer by layer, with a layer thickness of $1 \mu \mathrm{m}$. The toolpath included circular interpolations around the centre of the pocket. The direction of circular interpolation was changed alternatively from clockwise to counterclockwise at every new layer in order to homogeneously distribute the excess material induced by tool electrode wear on the pocket surface as previously done in [17]. Tool wear compensation was not applied for the machining process. Fig. 2 shows the experimental details. 


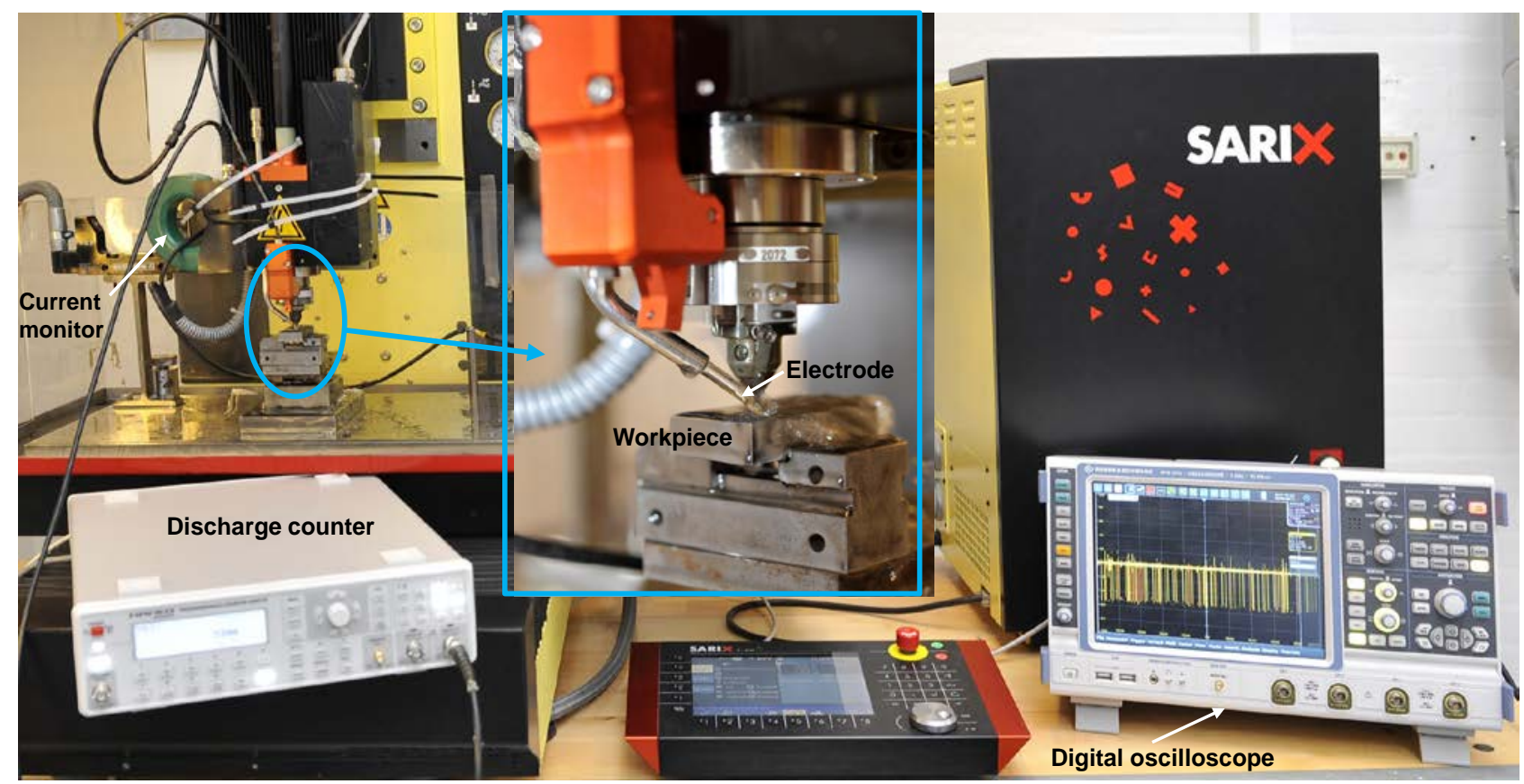

a.

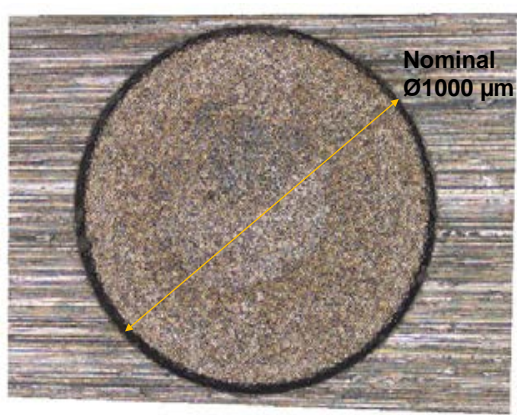

b.

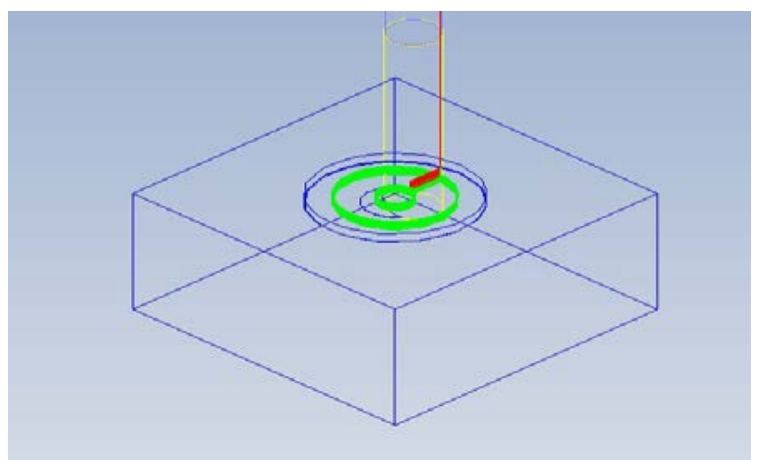

C.

Fig. 2 Experimental set-up a) SARIX SX-200 micro-EDM milling machine showing electrode and workpiece, b) circular pocket and c) tool path for machining of the circular pocket

To understand the performance of the micro-EDM process and to check the reliability of the experimental data, the waveforms are acquired and incompatibilities that could have occurred during the acquisition of data, if any, is searched. The acquisition has been done at a very low trigger level on current signals at $100 \mu \mathrm{A}$, in order to acquire all the discharge current waveforms. A MATLAB script is developed to classify the discharges based on their current peak, and to plot the histogram of the discharge waveforms.

The histogram provided information regarding frequency of waveforms with different peak currents. An example is shown in Fig. 3. The discharge waveforms of the current showed peak current ranging from 4.11 to $5.84 \mathrm{~A}$. The average value of the maximum peak current for five tests was $5.38 \mathrm{~A}$, with a standard deviation of $0.43 \mathrm{~A}$. Based on the discharge population 
characterization, for counting all the active discharges causing the tool electrode wear, the trigger level is chosen at a level of $1 \mathrm{~A}$, which is sufficiently above the noise level.

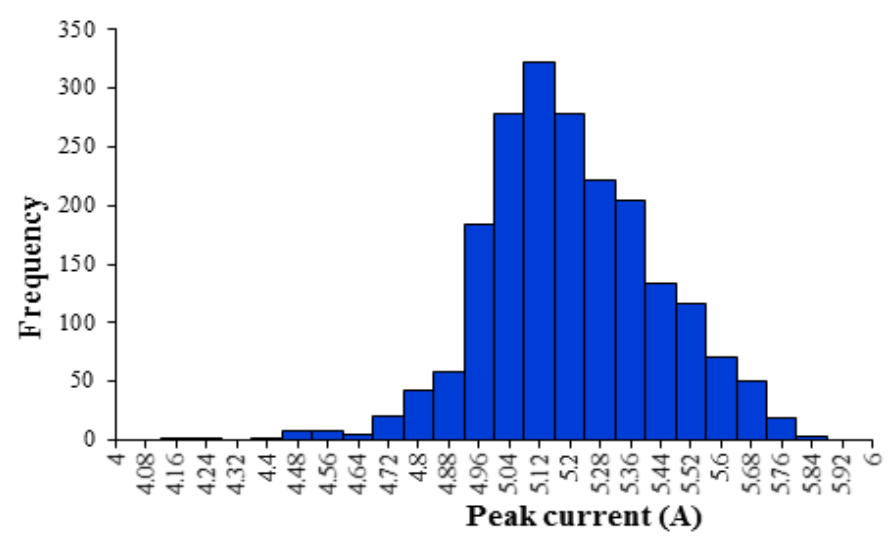

Fig. 3 Histogram of the current waveforms (average value of maximum peak current $=5.38 \mathrm{~A}$ )

\section{Simulation of machined surface profile}

The tool electrode wear compensation method based on TWD has the potential to be effectively used for machining of free form geometries by micro-EDM milling at different processing conditions. However, TWD estimation errors are reflected on the geometry of machined surfaces [16].Thus, it is necessary to understand and evaluate the progressions of propagation of the TWD estimation error along the toolpaths. The effect of TWD estimation error on the profile of the machined surface can be envisaged using a simulation tool developed by the authors.

In the investigation, a simple case is initially defined consisting of a straight slot of $1000 \mu \mathrm{m}$ in length and $10 \mu \mathrm{m}$ in nominal depth. In the simulations, the length of the slot was divided into segments and the depth into layers, all of equal dimensions. The toolpath was simulated using MATLAB. Table 1 shows the parameters used for simulation of the TWD compensation method. 
Table 1 Parameters for the TWD simulation

\begin{tabular}{|l|}
\hline $\begin{array}{l}\text { Tool wear per discharge }(\mathrm{TWD})=2.95 \mu \mathrm{m}^{3}(\text { based on earlier } \\
\text { results at the Department documented in [17]) }\end{array}$ \\
\hline Discharge gap $=5 \mu \mathrm{m}$ \\
\hline Diameter of the tool electrode $=300 \mu \mathrm{m}$ \\
\hline Number of layers $=10$ \\
\hline Number of segments $=10$ \\
\hline Length of each segment $=100 \mu \mathrm{m}$ \\
\hline Incremental depth $=1 \mu \mathrm{m}$ \\
\hline Error in estimation of TWD varied from 1 to $5 \%$ \\
\hline
\end{tabular}

Fig. 4 shows a schematic of the model showing the calculations of wear compensation length. In the model used for the simulations, the values of the various $\mathrm{z}$ locations of the surface at any instant is calculated based on the number of discharges causing volumetric material removal for the previous segment on a particular layer. Along toolpath, the applied tool electrode wear compensation for the current segment is calculated on the basis of the TWD and the number of discharges for the previous segment. The procedure is repeated for the entire cavity layer by layer. A constant value of material removal per discharge (MRD) is assumed [22]. The number of discharges $\left(N_{d}\right)$ is calculated by dividing the volume of work material removed ( $\left.\mathrm{V}_{\text {removed }}\right)$ in the previous segment by the MRD. The number of discharges are used for the calculation of the tool wear length and tool electrode wear compensation.

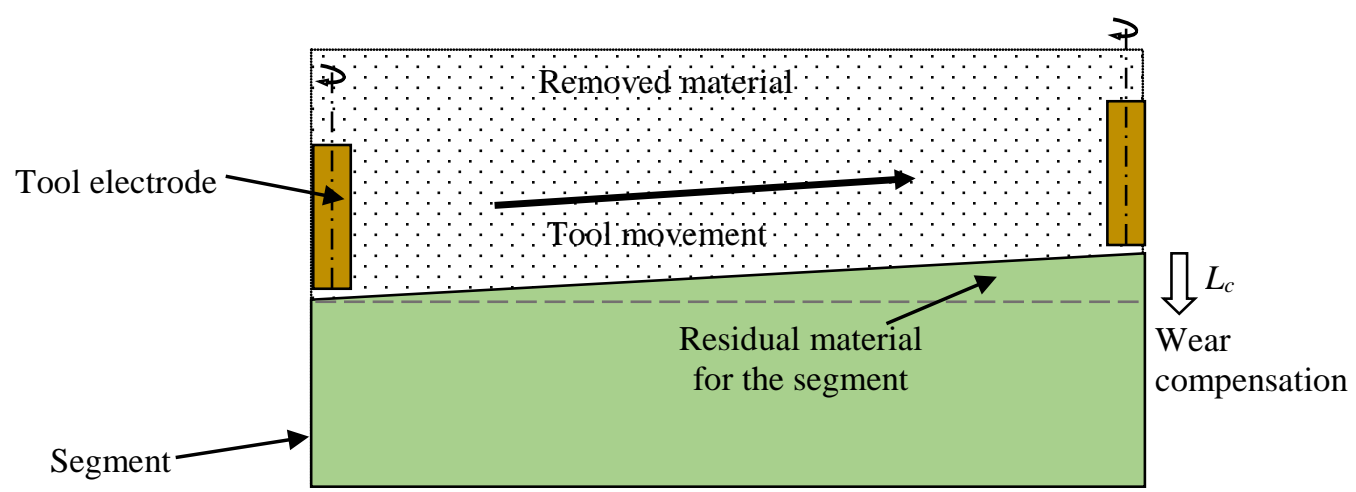

Fig. 4 Schematic representation of the method of calculation of length of wear compensation for a segment in the model for the simulations

The length of tool wear is evaluated as,

$$
\text { Length of tool wear }\left(L_{w}\right)=\left(N_{d} T W D\right) / A_{e}
$$


where, TWD is the actual tool wear per discharge without error, and $A_{e}$ is the area of cross-section of the tool electrode. The length of the applied tool wear compensation would carry the error associated with the estimation of TWD. Therefore,

Length of the applied tool wear compensation,

$$
L_{c}=\left(N_{d} T W D_{e}\right) / A_{e}
$$

where, $T W D_{e}$ is the tool wear per discharge including an error in estimation. The length $L_{c}$ is calculated and applied at the end of each segment.

Thus, the next position of the profile of the surface is calculated as,

$$
Z_{\text {next }}=Z_{\text {current }}-L_{w}+L_{c}
$$

where, $Z_{\text {next }}$ is the next $\mathrm{z}$-position on the machined surface profile, and $\mathrm{Z}_{\text {current }}$ is the current $\mathrm{z}$ position of the profile. The equation (3) is illustrated using a schematic, see Fig. 5.

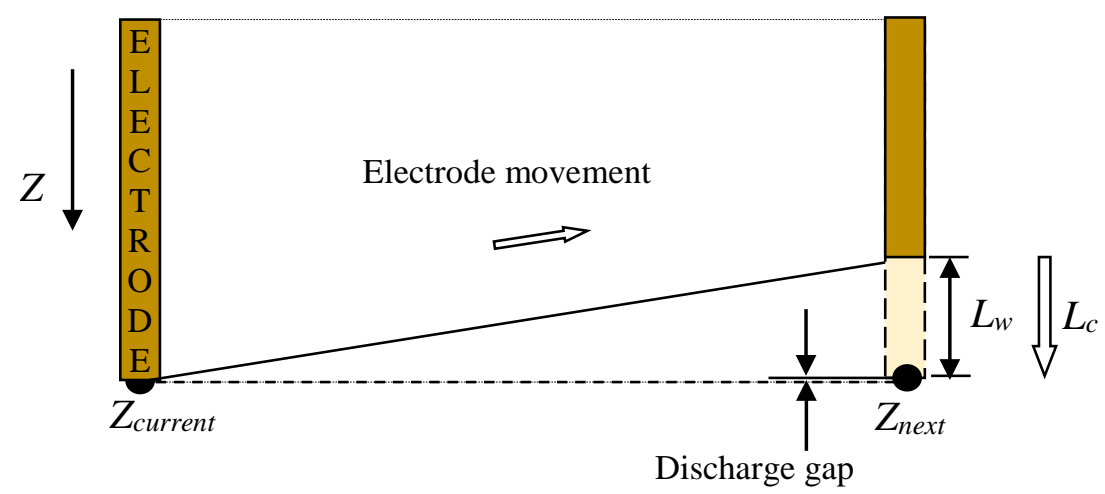

Fig. 5 Illustration of the electrode wear compensation method using TWD method

Fig. 6 shows the results of the simulation for a machined surface of 10 segments and 10 layers. As can be observed from Fig. 6, the ideal profile of the surface machined without any initial estimation error is shown by the dashed lines. Considering an initial error in the estimation of TWD of $+5 \%$, at the end of the $10^{\text {th }}$ layer, the calculated depth of the slot machined is $10.52 \mu \mathrm{m}$. Thus, for such a small depth, the percentage depth error (+5.24\%) is close to the initial TWD estimation error 
$(+5 \%)$ as the error propagates over the ten segments and ten layers. The effect of TWD estimation error on the depth error for an increasing number of layers is discussed in the next section.

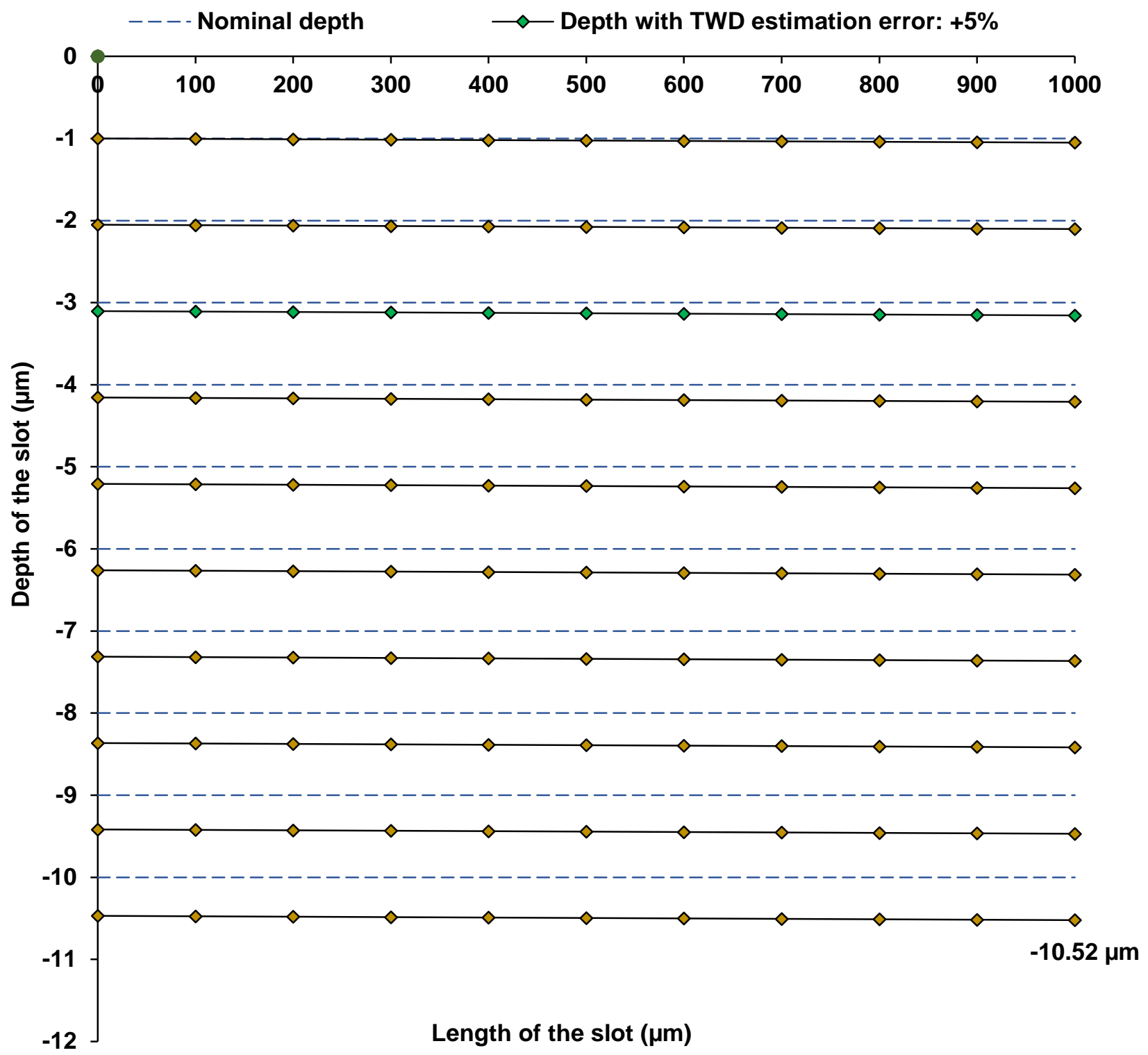

Fig. 6 Simulation results of the effect of TWD estimation error on the profile of machined surface $($ error $=+5 \%$, number of steps $=10$, number of layers $=10)$ 


\section{TWD error propagation - simulations and validation}

The simulation of TWD based tool wear compensation using process parameters settings shown in Table 1 is further extended to 50 segments and 50 layers.

The simulation is performed to understand the effect of error in the estimation of TWD on the depth of the slot. In Fig. 7 the results of simulation for machining of layers from 41 to 50 is presented. The calculated final depth of the slot is $66.5 \mu \mathrm{m}$, and thus the total error on the depth of the slot is $16.5 \mu \mathrm{m}$, corresponding to $+33 \%$,. Table 2 and Fig. 8 and Fig. 9 show the effect on the depth error as a function of the initial TWD error for the 50 layers slot. As the TWD estimation error increases from $+1 \%$ to $+5 \%$, the error in final calculated depth of the slot amplifies from $+5.24 \%$ to $+33 \%$.

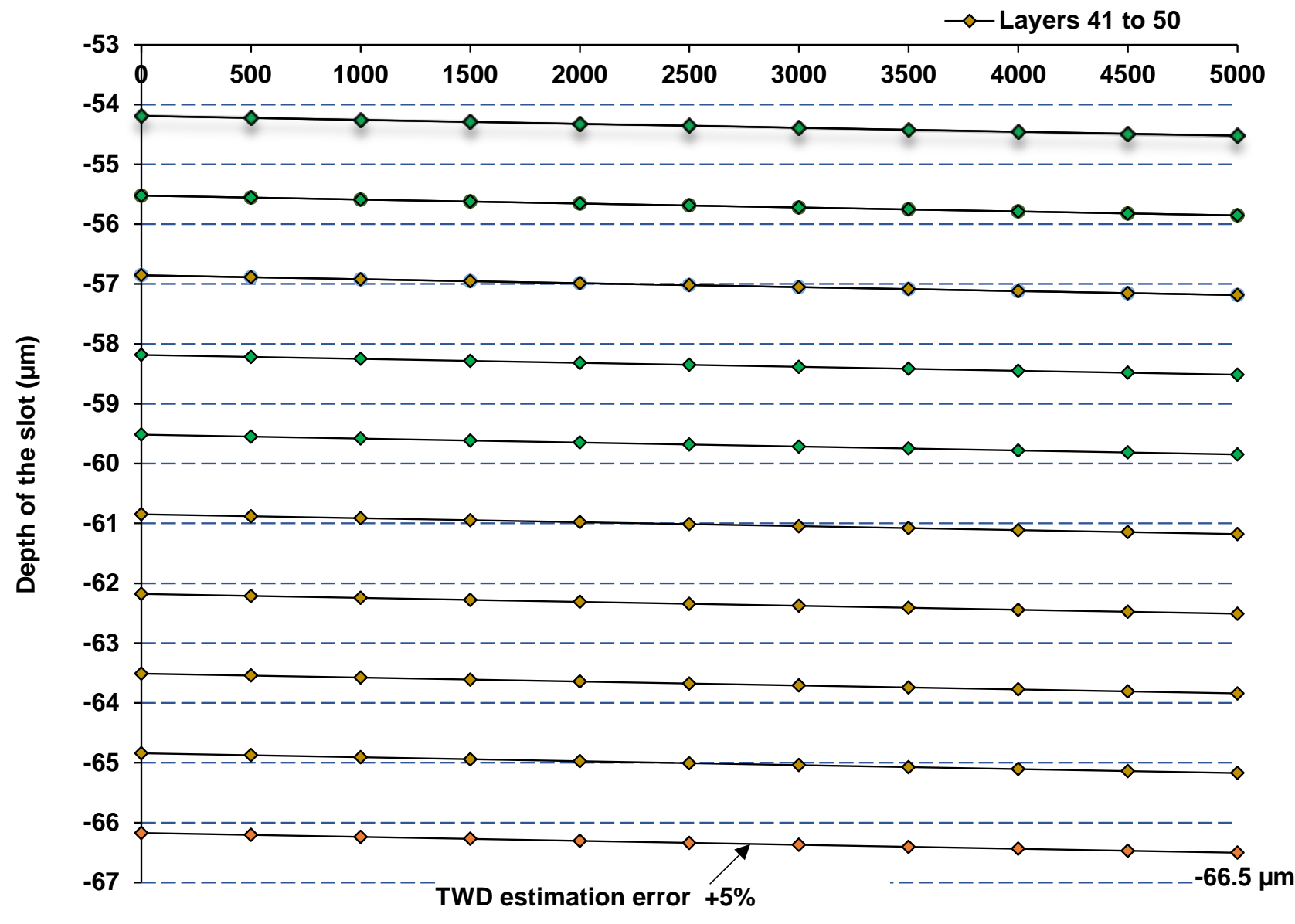

Length of the slot $(\mu \mathrm{m})$

Fig. 7 The profile of the simulated micro EDMilled surface using TWD method (initial TWD estimation error $=+5 \%$, Nominal depth $=50 \mu \mathrm{m}$, Number of layers $=50$ ) 
Table 2 Summary of results of simulation - effect of TWD estimation error estimated at $50 \mu \mathrm{m}$ depth (number of segments $=50$, number of layers $=50$ )

\begin{tabular}{|c|c|c|}
\hline $\begin{array}{c}\text { Simulation } \\
\text { run }\end{array}$ & $\begin{array}{c}\text { TWD } \\
\text { estimation } \\
\text { error } \\
(\%)\end{array}$ & $\begin{array}{c}\text { Error in } \\
\text { final depth } \\
\text { of the slot } \\
(\%)\end{array}$ \\
\hline 1 & +1 & +5.24 \\
\hline 2 & +2 & +11.04 \\
\hline 3 & +3 & +17.52 \\
\hline 4 & +4 & +24.80 \\
\hline 5 & +5 & +33.00 \\
\hline
\end{tabular}

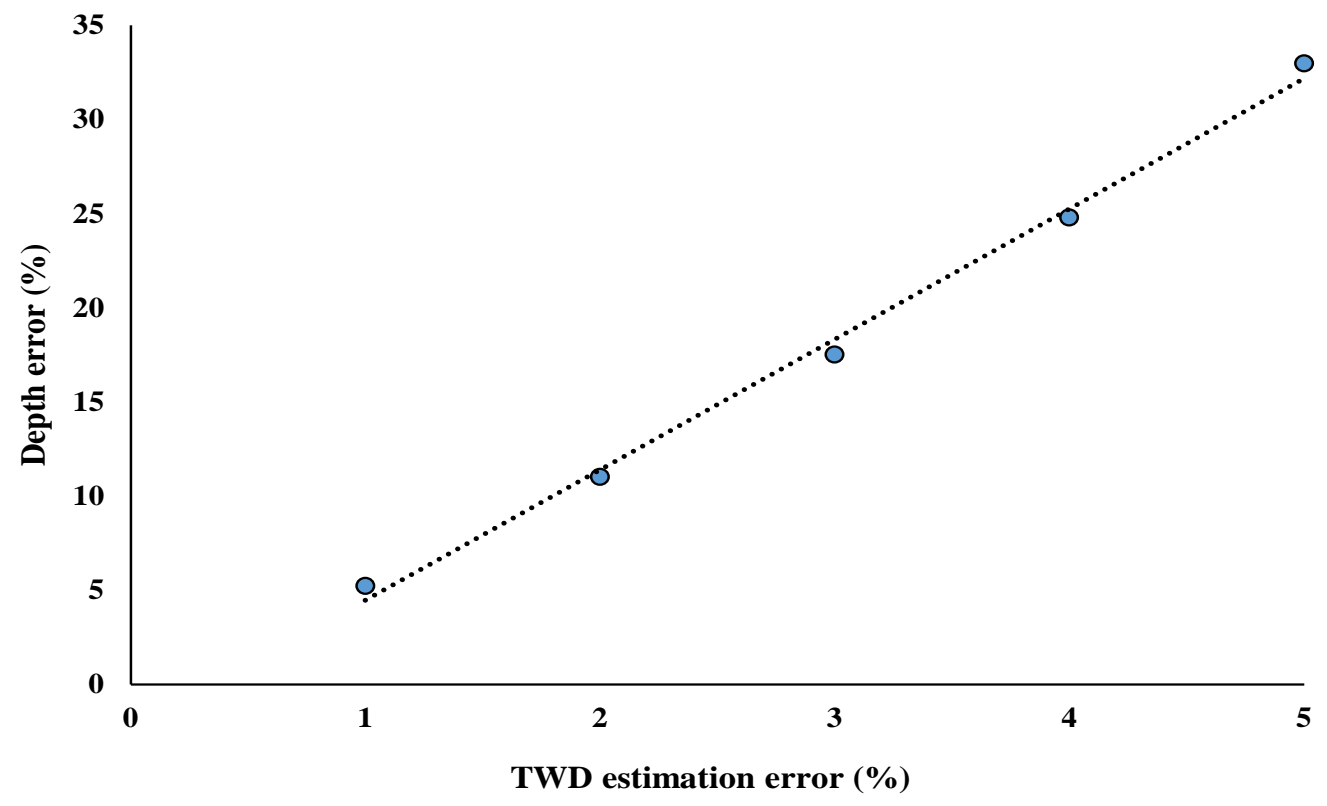

Fig. 8 The amplification of depth errors with TWD estimation errors through 50 layers 


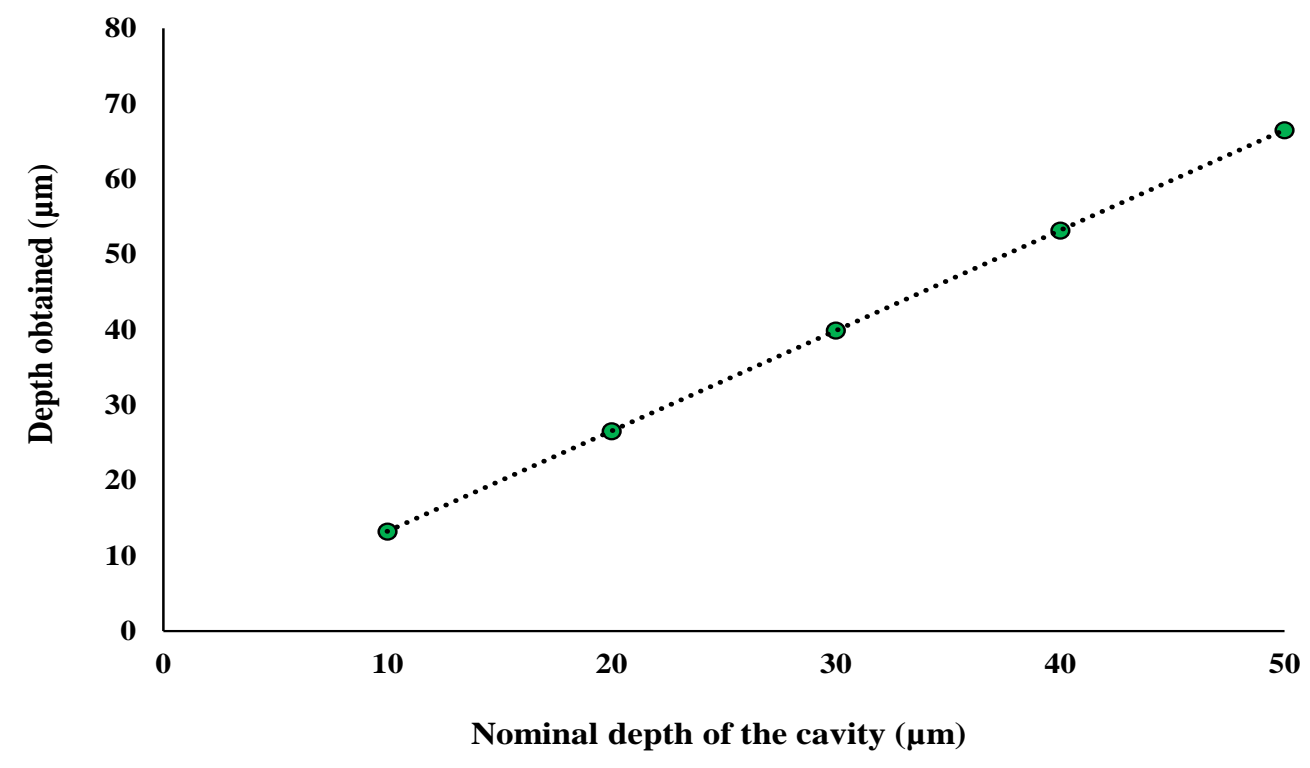

Fig. 9 Increase in actual depth of the cavity in comparison with nominal depth for TWD error $5 \%$

The results of simulation of the final machined surface profile by considering the effect of TWD estimation error varying from $-15 \%$ to $+15 \%$ is shown in Fig. 10, for 50 layers. The range of $-15 \%$ to $+15 \%$ error on the TWD was taken into consideration for the simulation to accommodate the practical maximum possible estimation errors on the TWD in both positive as well as the negative directions, and to evaluate the propagation of positive as well as the negative errors with an increase in the nominal depth of the cavity. With an increase in TWD estimation error from 0 to $-15 \%$, the final depth of the slot is less than the nominal depth and increases slightly along the slot. A TWD estimation error of $-15 \%$ causes a decrease in the calculated depth by $-43 \%$. On the other hand, TWD estimation error of $+15 \%$ leads to an increase in calculated depth of the slot by $+286 \%$. A small variation in the TWD estimation results in a larger variation on the depth, and therefore, at larger depths, the allowed error on TWD becomes tighter. 


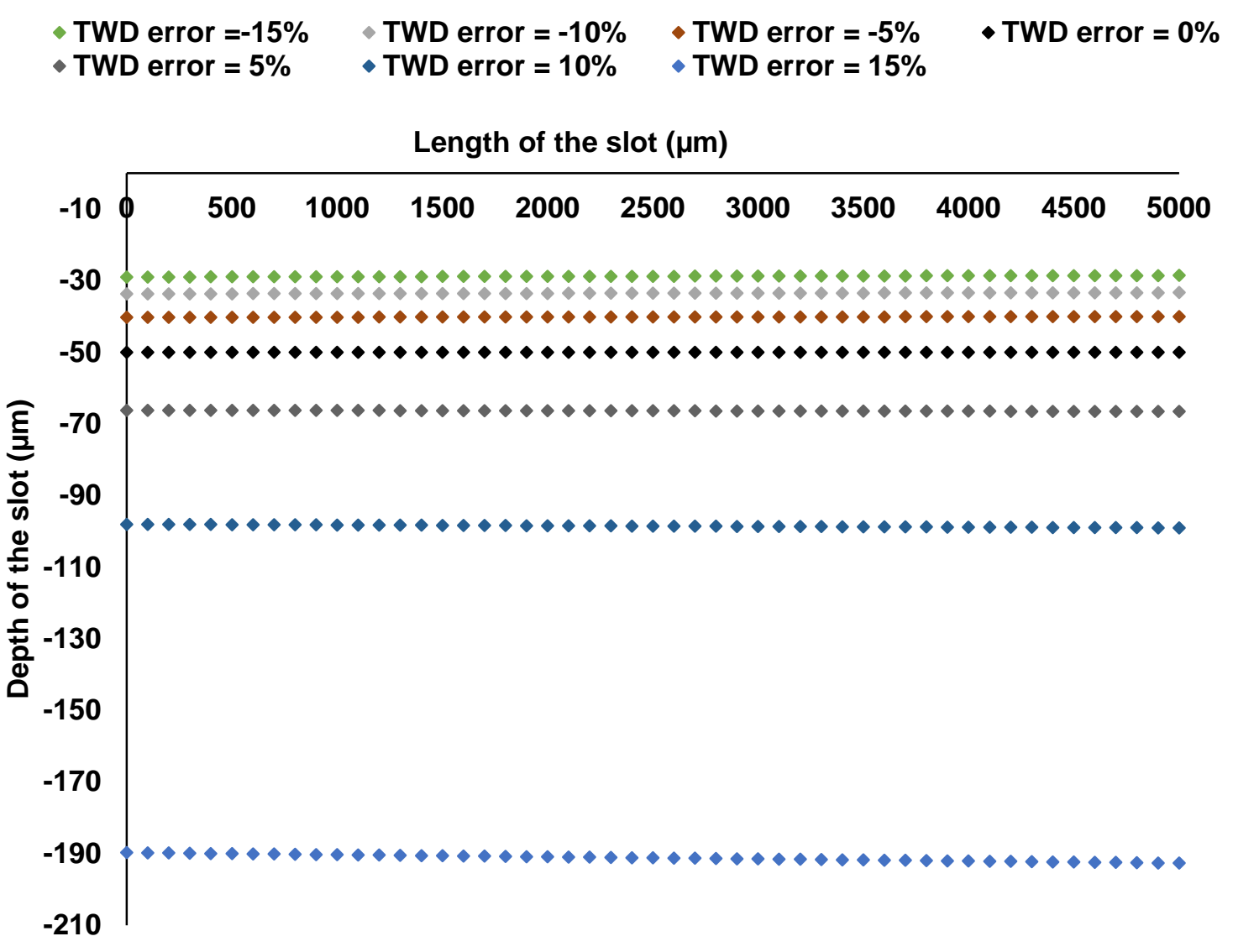

Fig. 10 Results of simulation of the final machined surface profile by considering the effect of TWD estimation error (number of segments $=50$, number of layers $=50$, TWD estimation error $=$

$$
-15 \% \text { to }+15 \%)
$$

The effect of TWD error with increasing nominal depth (or number of layers) is shown in Fig. 11 where the number of layers were varied from 10 to 50. For these set of simulation trials, the TWD estimation error is assumed constant at 5\%. The simulation results show that the actual simulated depth of the cavity increases along the length of the slot. For machining of 10 layers with each layer of thickness $1 \mu \mathrm{m}$ (nominal depth $10 \mu \mathrm{m}$ ), the depth at the middle of the cavity (at a length of 2500 $\mu \mathrm{m})$ is $13.1 \mu \mathrm{m}$ and the depth of the cavity at a length of $5000 \mu \mathrm{m}$ is $13.2 \mu \mathrm{m}$. Furthermore, for machining of 50 layers (nominal depth $50 \mu \mathrm{m}$ ), the depth at the middle of the cavity is $66.3 \mu \mathrm{m}$ and the depth of the cavity at a length of $5000 \mu \mathrm{m}$ is $66.5 \mu \mathrm{m}$. It is evident that the difference between nominal depth of the cavity and the simulated depth of the cavity increases from $3.2 \mu \mathrm{m}$ to $16.5 \mu \mathrm{m}$ (four-fold increase) simply with an increase in the number of layers, though the TWD estimation error remains constant at $5 \%$. This is due to the accumulation of the depth error through subsequent layers. Therefore, as the depth of the cavity increases, a tighter control on the TWD estimation error 
is essential in order to avoid a larger error on the actual depth of the cavity for accurate generation of micro parts using micro-EDM milling.

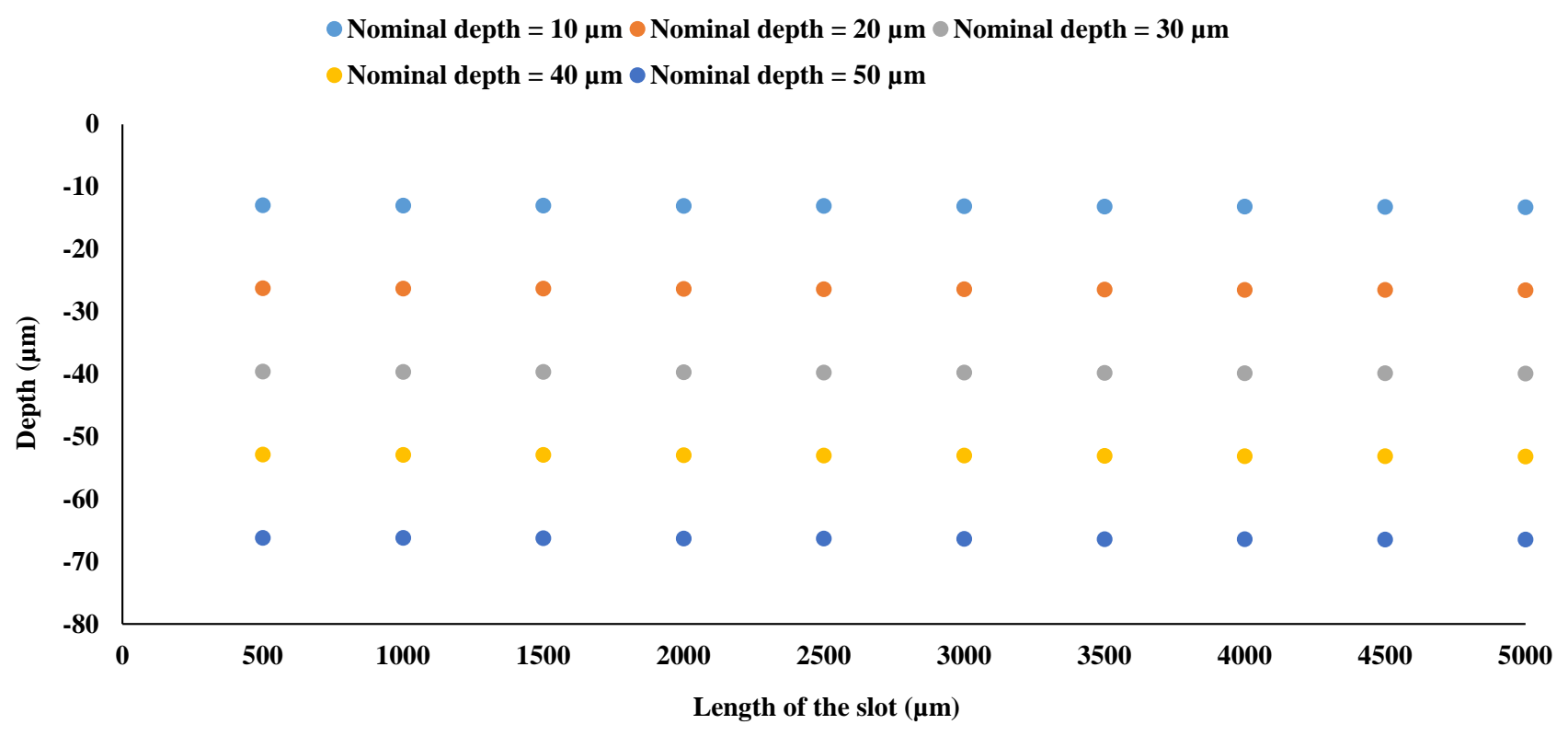

Fig. 11 Results of simulation of error propagation (TWD estimation error of 5\%) at various depths of cavity - simulated profiles (number of layers varied from 10 to 50)

In the statistical approach for electrode wear compensation in micro-EDM milling, material removal per discharge (MRD) is a parameter, which is directly correlated to the average energy of the discharge population [17, 22]. Real time material removal rate can be obtained by counting the number of discharges and multiplying by the average MRD of the discharge population. Fig. 12 shows an explanation of the MRD for a linear trajectory segment. Because of the tool wear, the vertical level of the machined surface increases by ' $\Delta z$ '. In the model presented here, the number of counted discharges for each segment is multiplied by the average MRD to obtain the 'removed volume of material' for the segment considered. Therefore, MRD is an important parameter influencing the model's predictions. 


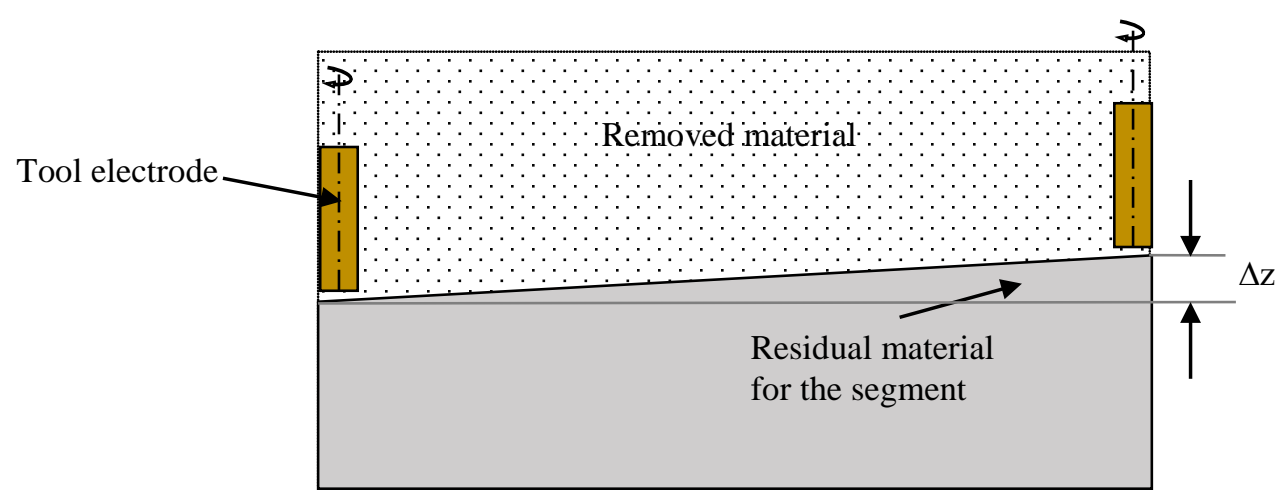

a.

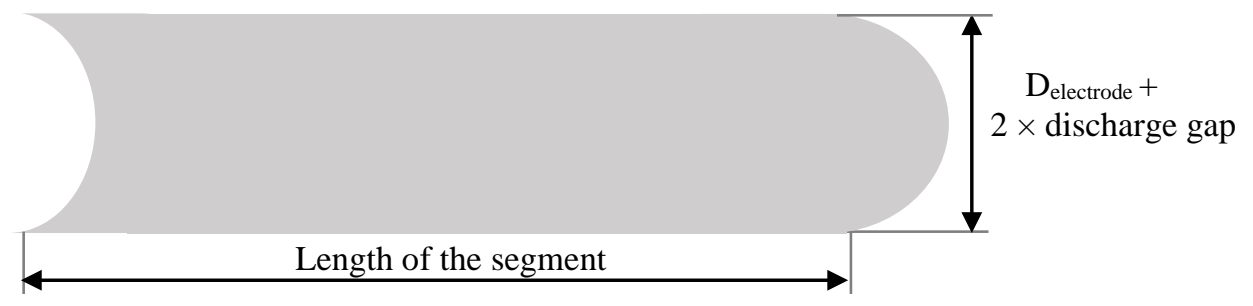

b.

Fig. 12 Explanation of MRD, a) undercompensated segment indicating the removed material and residual material, b) top view of the machined slot

In this work, a constant value of material removal per discharge (MRD) of $13 \mu \mathrm{m}^{3}$ was assumed for all the simulations, based on the earlier results obtained in [17, 22]. The effect of MRD estimation error on the depth error has been studied. Table 3 shows the parameters used for simulation of the effect of MRD estimation error on the depth error. In the simulations, the depth of the cavity was varied from $10 \mu \mathrm{m}$ to $100 \mu \mathrm{m}$.

Table 3 Parameters for simulation of the effect of MRD estimation error on depth error

\begin{tabular}{|l|}
\hline Discharge gap $=5 \mu \mathrm{m}$ \\
\hline Diameter of the tool electrode $=300 \mu \mathrm{m}$ \\
\hline Number of layers $=10$ to 100 \\
\hline Number of segments $=10$ \\
\hline Length of each segment $=100 \mu \mathrm{m}$ \\
\hline Incremental depth $=1 \mu \mathrm{m}$ \\
\hline TWD estimation error constant at $+5 \%$ \\
\hline Error in estimation of MRD varied from $-15 \%$ to $+15 \%$ \\
\hline
\end{tabular}

Fig. 13 shows the results of simulation of the effect of MRD estimation error on the error in the calculated depths of the cavity. An error in the MRD estimation from $-15 \%$ to $15 \%$ causes an error in the calculated depth of the cavity from $+1 \%$ to $-1 \%$. The same error in the calculated depth of 
cavity was observed for all simulations at different depths of cavity from $10 \mu \mathrm{m}$ to $100 \mu \mathrm{m}$. Thus, the results of simulation show that the effect of MRD estimation error on the error in the depth of the cavity could be negligible for this investigation.

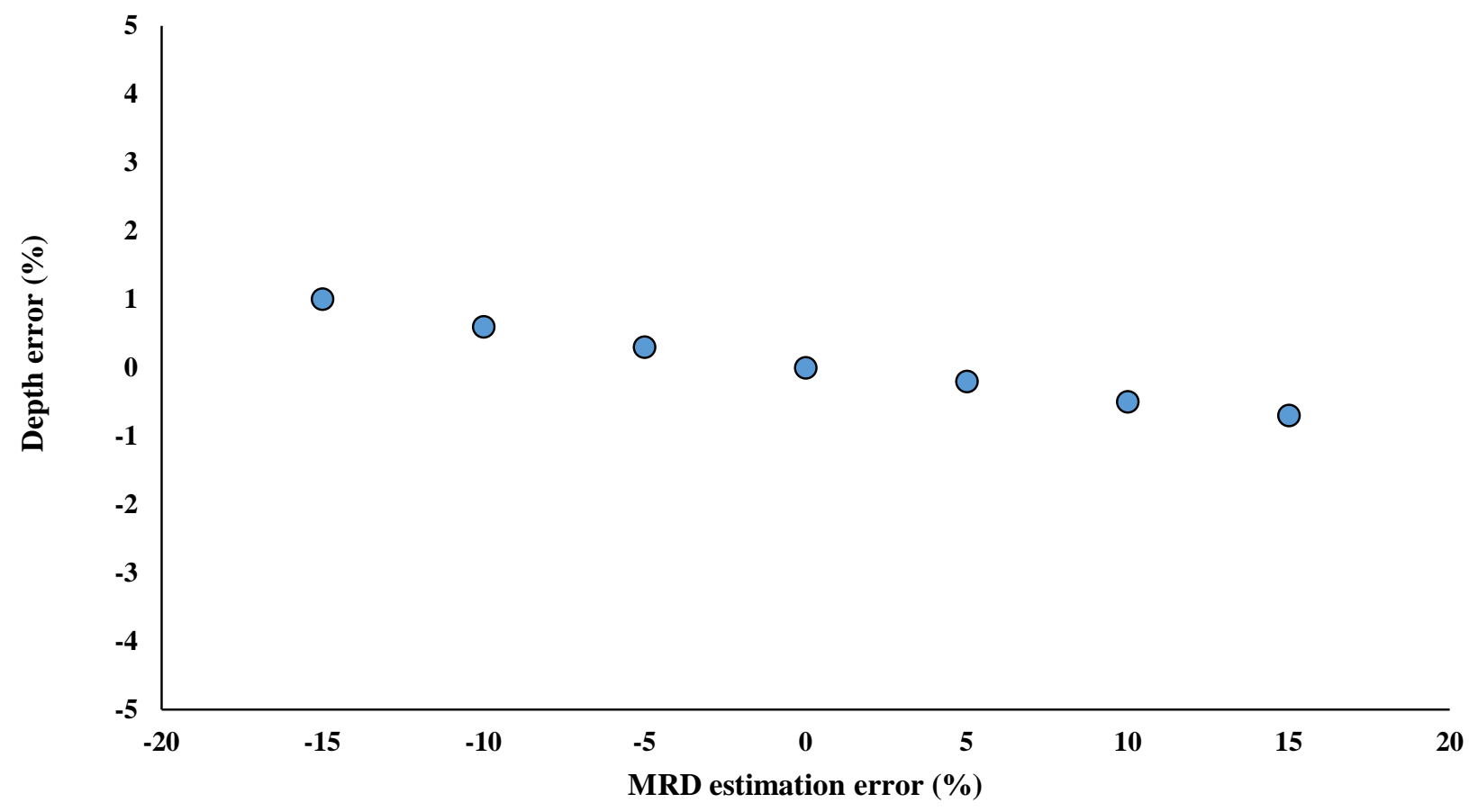

Fig. 13 Results of simulation of the effect of MRD estimation error on the depth error (number of layers varied from 10 to 100 )

In the following, the model developed to evaluate the effect of initial TWD estimation error on the profile of machined surface in micro EDM milling is experimentally validated. Slot machining experiments were performed on a SARIX SX-200 micro-EDM machine. Tungsten carbide rods of $\varnothing 300 \mu \mathrm{m}$ and Stavax steel blocks are used as the tool material and workpiece material respectively. The programming for machining along the segments and along each layer is done using $G$ codes. The parametric conditions presented in Table 1 is again used to perform the experiment. The number of discharges were counted using a HAMEG HM8123 programmable counter. A MATLAB script is prepared to count the number of discharges corresponding to the machining of each of the segments. After machining each segment, the tool wear compensation applied is calculated based on TWD method and then is applied at the end of machining of each segment.The length of the slot is $5000 \mu \mathrm{m}$, and 14 layers were machined in total. 
The micro EDM milled surface profile is measured using Alicona focus variation microscope. The IFM G4 20X optic is used to capture the profile. The measurement is performed at 11 positions on the workpiece surface. The positions were the left end of the slot (length of the slot $=0 \mu \mathrm{m}$ ) and then after every 5 segments from left end along the entire length of $5000 \mu \mathrm{m}$ of the slot (length of the slot $=5000 \mu \mathrm{m})$. The software used for measurement of the surface profile as well as the depths has been SPIP 3D software. Fig. 14 shows an example of the image of the machined slot and profile of the cross-section indicating the machined depth.

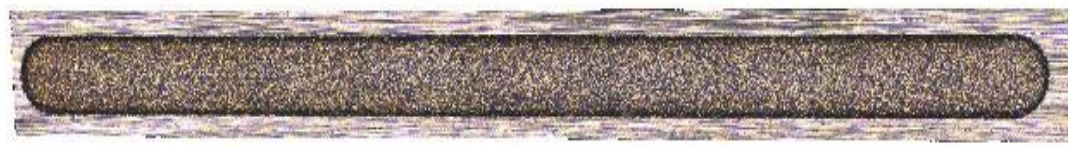

a.

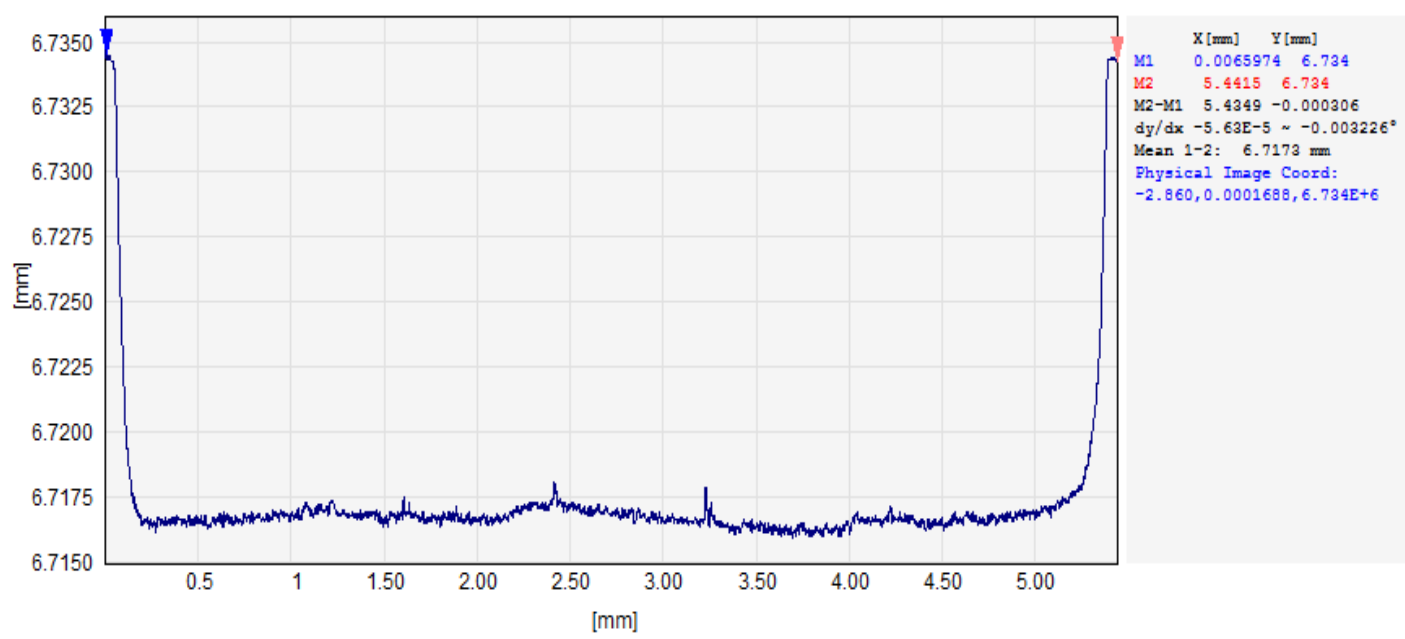

b.

Fig. 14 An example of machined slot a) image of the machined slot, and b) Profile of the cross-section indicating the machined depth

The results of the experimental validation, consisting of 5 repetitions of the slot machining test, are presented in Fig. 15. The initial TWD estimation error of $+5 \%$ is propagated along different segments and layers.

The depth of the slot predicted using the simulation tool and the measured depth from the experiments match well. At the centre of the slot, there is an extremely good match between the predicted and experimentally obtained values. However, at the beginning and end of the slot, many of the experimental data points show either an overestimation or underestimation with the predicted 
values. For positions along the slot from $0 \mu \mathrm{m}$ to $1500 \mu \mathrm{m}$, an underestimation of the experimentally measured depth is observed whereas for positions along the slot between $3500 \mu \mathrm{m}$ to $5000 \mu \mathrm{m}$, an overestimation of the depth is obtained. This effect could be due to i) a variation in the number of normal pulses with an increase in length of the slot [18], ii) occurrence of more debris at the end of the slot [19], iii) variations in number of discharges and energy of discharges with gap distance as a result of accumulation of debris on the slot [20-21].

In our experiments the slots were aligned along the $\mathrm{x}$ direction while the dielectric flow was oriented with a component of the fluid velocity in the $\mathrm{x}$ positive direction as shown in the Fig. 16. This implied accumulation of the debris towards the end of the slot. As a consequence, the actual slot depth is reduced towards its end due to energy loss in remelting the debris. When starting a new layer, the correction used $\left(L_{c}\right)$ is the one referring to the last step of the previous layer. As the start of the slot is clean from debris, this results in an overcompensation producing a depth error.

As the machining progresses, the accumulation of the debris particles at the end of the slot increases which causes variations in the proportions of the numbers of normal discharges and shortcircuits. Also, a transfer of a fraction of energy of the discharges to the debris leads to lower transfer of energy for the removal of workpiece material. However, this phenomenon needs a further comprehensive investigation on the estimation of the change in the number of discharges along the length of the slot during machining of each layer. 


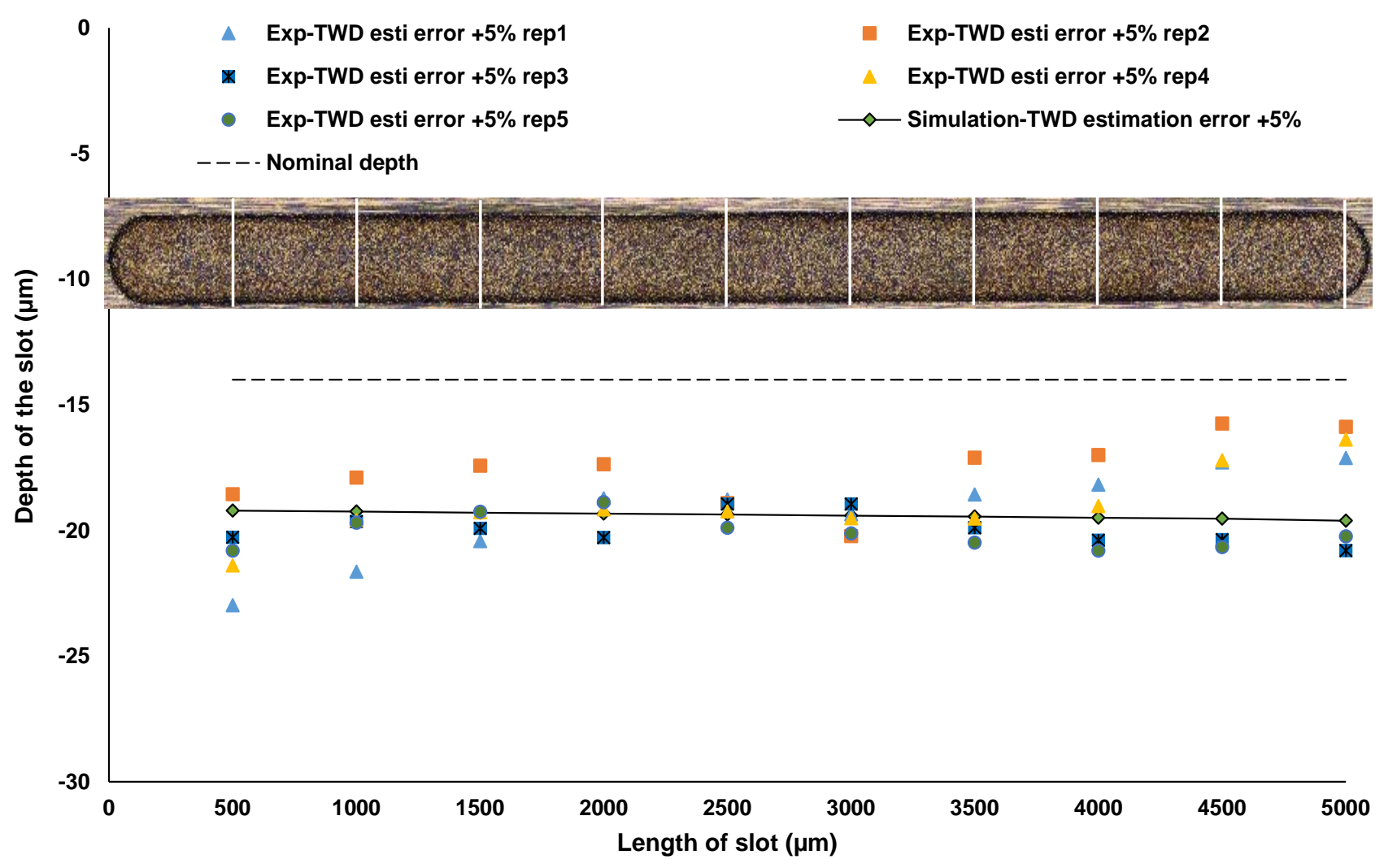

Fig. 15 Validation of the TWD error estimation model using experiments (Total number of layers machined $=14$, TWD estimation error $=+5 \%$ )

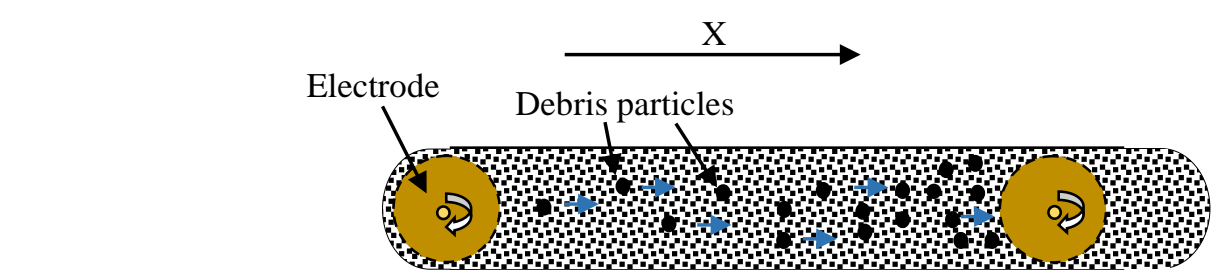

Dielectric flow velocity

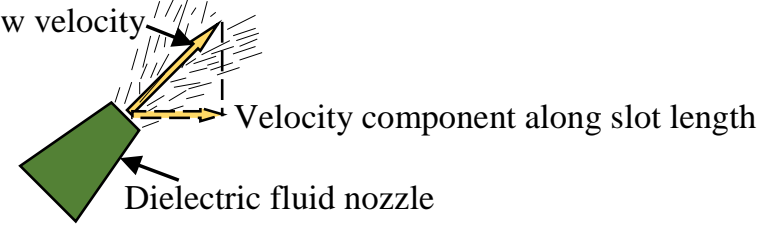

Fig. 16 Accumulation of debris towards end of the slot 


\section{TWD determination}

In this section, the developed simulation tool, presented in section 3 is used for determination of correct TWD using simple experiments. The steps of this scientific and iterative technique is briefly elucidated in the flow diagram in Fig. 17.

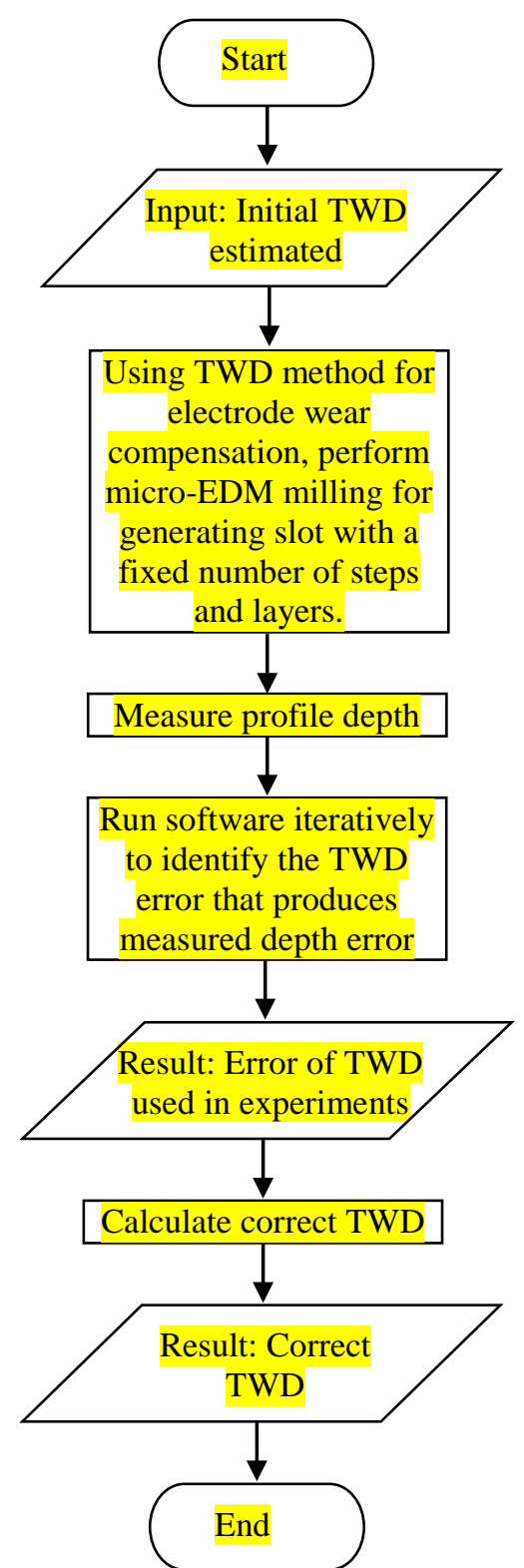

Fig. 17 Flow diagram of the method of determination of correct TWD

To demonstrate the method, the average value of TWD for micro EDM milling experiments corresponding to energy index of 105 of $2.95 \mu \mathrm{m}^{3}$, as reported in Ref. [17], is used for carrying out 
a standard slot machining experiment. The depth of the generated slot is measured on several positions along its length by means of a confocal microscope. Starting from the initially estimated value of TWD the simulation tool is run for the specific slot generated with different values of the expected TWD estimation error, until a close match between the simulated and measured depths is found.

The simulation was performed iteratively based on the formulas listed below (see Fig. 18 a for the method of simulation calculations). For the very first step of the simulation, the calculated electrode wear length is assumed to be negligible and hence, number of discharges for the first step of simulation $\left(N_{d 1}\right)$ is determined using the MRD and is calculated as:

$$
N_{d 1}=\left(w \times I_{d} \times \Delta x\right) / M R D
$$

(4)

where, $w$ is the width of the slot in $\mu \mathrm{m}, I_{d}$ is the layer thickness in $\mu \mathrm{m}, \Delta x$ is the segment length in $\mu \mathrm{m}$ and MRD is the material removal per discharge in $\mu \mathrm{m}^{3}$.

The length of linear electrode wear $\left(L_{w}\right)$ in $\mu \mathrm{m}$, length of applied compensation $\left(L_{c}\right)$ in $\mu \mathrm{m}$ and the next position of the profile of the cavity are calculated according to equations (1), (2) and (3) presented earlier in section 3.

The volume of material removed for a generic step and on a layer (see Fig. 18 b) is calculated as:

$$
\left.V_{\text {rem }}=(w \times \Delta x) \times \text { abs }\left(\left(Z_{i, j}-Z_{i-1, j}+Z_{i, j-1}-Z_{i-1, j-1}\right) / 2\right)\right)
$$

where, $Z_{i, j}$ is the calculated position of the profile of the cavity at the end of the current step and at the end of the current layer and $Z_{i-1, j}$ is the calculated position of the profile of the cavity at the end of the current step and at the beginning of the current layer. Similarly, $Z_{i, j-1}$ is the calculated position of the profile of the cavity at the beginning of the current step at the end of the current layer, and $Z_{i-1, j-1}$ is the calculated position of the profile of the cavity at the beginning of the current step and the beginning of the current layer. The term 'abs $\left.\left(\left(Z_{i, j}-Z_{i-1, j}+Z_{i, j-1}-Z_{i-1, j-1}\right) / 2\right)\right)$ ' in equation (5) represents the calculated area of the trapezoid enclosing the points on the profile in the Z-X plane. 


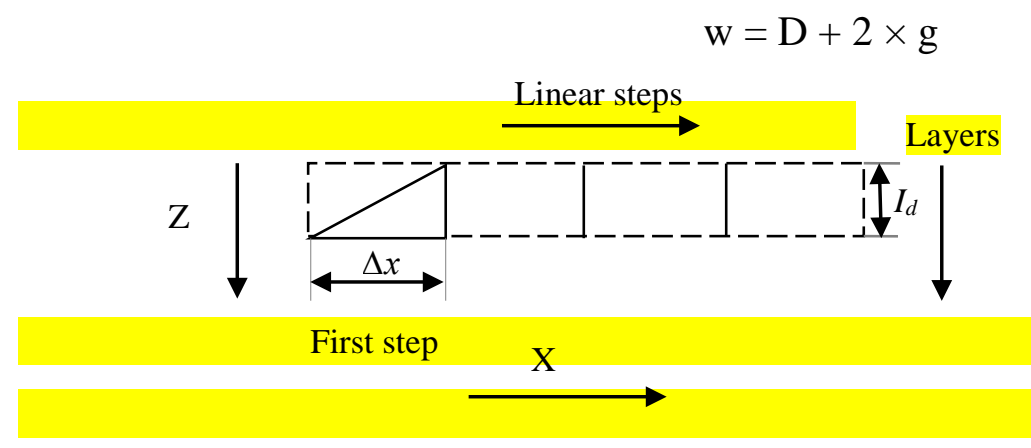

a.

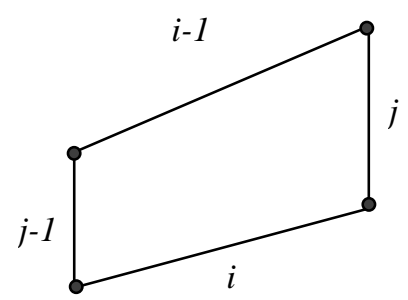

b.

Fig. 18 Method of tool wear compensation using the simulation calculations a) along linear steps and layers, b) points enclosing a trapezoidal area in Z-X plane for calculation of volume of material removed for a generic step and a layer (indices $i$ and $j$ represent ‘layer’ and ‘step’ respectively).

The number of discharges $\left(N_{d}\right)$ required to remove the calculated volume $V_{\text {rem }}$ is:

$$
N_{d}=V_{\text {rem }} / \mathrm{MRD}
$$

For $n$ number of layers and $m$ number of steps, at the end of every layer, the incremental depth $\left(I_{d}\right)$ is added to the current calculated position of the profile $Z_{i-1, m}$. Accordingly, at the beginning of a new layer, the calculated position of the profile becomes:

$$
Z_{i, 1}=Z_{i-1, m}+I_{d}
$$

The measured depth error $\left(e_{z}\right)$ is determined from the experiements as:

$$
e_{z}=\left(\left(Z_{\text {measured }}-Z_{\text {simulated }}\right) / Z_{\text {simulated }}\right)
$$

Now, the software is run iteratively to obtain the TWD error $\left(e_{T W D}\right)$ that generates $e_{z}$. When a match is found between the measured and simulated depths, the corresponding TWD estimation error is 
recorded and the correct value of the TWD is recalculated. The method is applied for the processing conditions shown in table 4.

Table 4 Experimental processing conditions for determination of TWD and results

\begin{tabular}{|c|c|c|c|c|}
\hline $\begin{array}{c}\text { Energy } \\
\text { index }\end{array}$ & $\begin{array}{c}\text { Total } \\
\text { length of } \\
\text { the slot }\end{array}$ & $\begin{array}{c}\text { Number } \\
\text { of } \\
\text { layers }\end{array}$ & $\begin{array}{c}\text { Tool wear } \\
\text { compensation }\end{array}$ & $\begin{array}{c}\text { Number of } \\
\text { repetitions }\end{array}$ \\
\hline 105 & $1000 \mu \mathrm{m}$ & 19 & TWD based & 5 \\
\hline \multicolumn{3}{|c|}{$\begin{array}{c}\text { Nominal depth }=19.00 \mu \mathrm{m} \text {, Actual depth measured }=19.20 \mu \mathrm{m}, \\
\text { with a standard deviation }=0.433 \mu \mathrm{m}, \mathrm{TWD}=3.43 \mathrm{~m}^{3}\end{array}$} \\
\hline
\end{tabular}

The error on the depth of the cavity is observed to be the minimum (within 1\%) corresponding to a TWD of $3.43 \mu \mathrm{m}^{3}$. The comparison between nominal, simulated and experimentally machined and measured profiles are shown in Fig. 19.

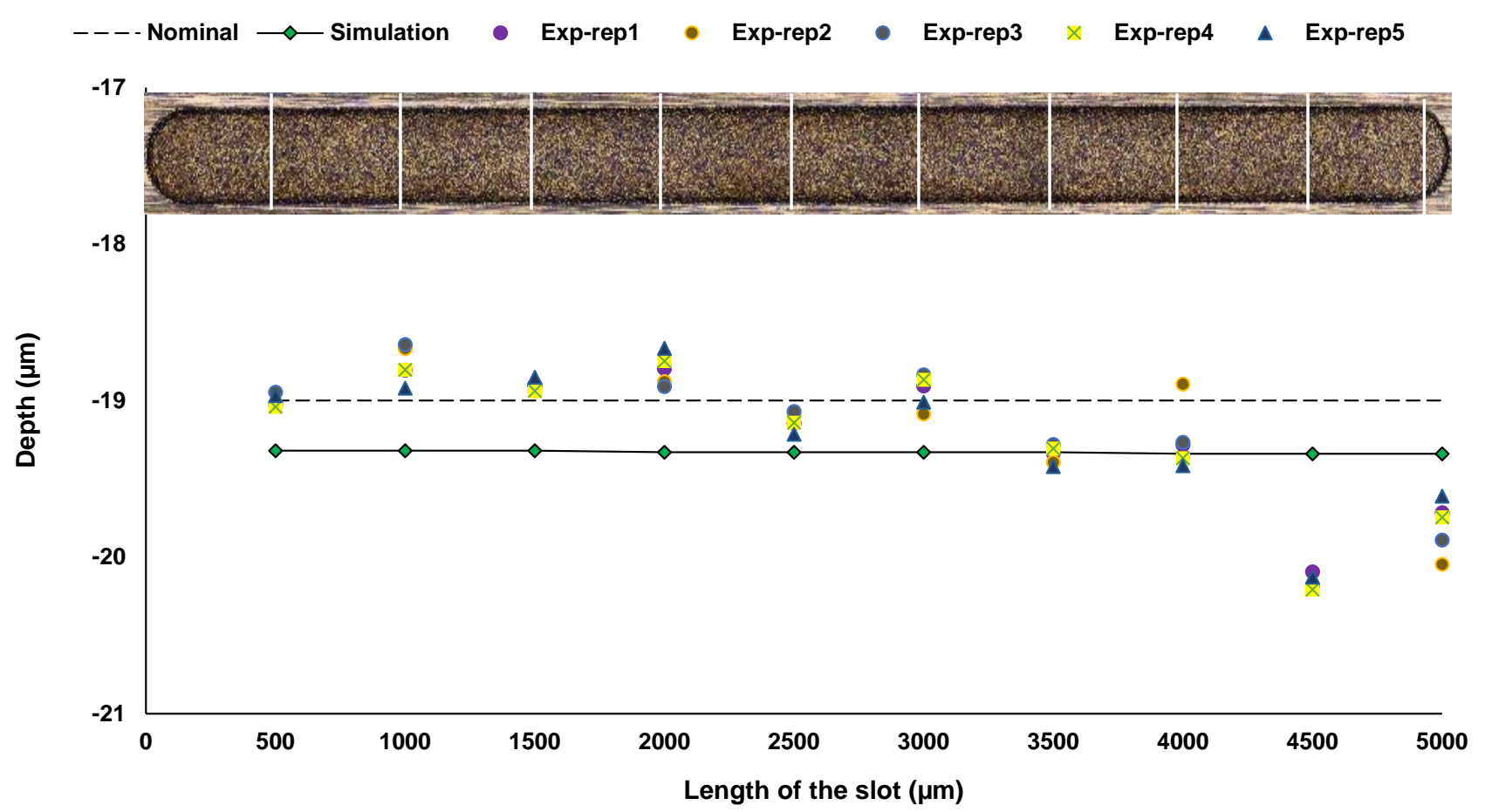


Fig. 19 The nominal, simulated and experimentally measured depths at TWD $=3.43 \mu \mathrm{m}^{3}$ (number of layers machined $=19$ )

\section{Conclusions}

This paper presented a simulation-based investigation on the effect of initial TWD estimation error on the machined depth in micro electrical discharge milling process. Based on this work, the following remarks have been determined:

- The results of simulation of machined surface profile show that TWD estimation error is propagated and amplified over the segments and layers, and finally is reflected on the simulated machined surface profile.

- Based on the developed simulation tool, an indirect method has been proposed for evaluation of the correct TWD. The simulation results were validated by performing slot machining experiments.

- The depth of the profile predicted using the simulation and the machined depth obtained using experiements show an extremely good match at the centre of the slot. However, at the ends of the slot, an overestimation or underestimation is observed. This could be further investigated and implemented for real time electrode wear compensation in micro-EDM milling.

- The MRD error has no effect on the error in the depth of the machined slots.

\section{Acknowledgements}

The research leading to these results has received funding from the People Programme (Marie Curie Actions) of the European Union's Seventh Framework Programme (FP7/2007-2013) under REA grant agreement no. 609405 (COFUNDPostdocDTU).

\section{References}


[1] Bissacco, G., Valentincic, J., Hansen, H. N. and Wiwe, B. D. (2010), Towards the effective tool wear control in micro-EDM milling, International Journal of Advanced Manufacturing Technology, v47, n1-4, pp.3-9.

[2] Dauw, D. and Snoyes, R. (1986), On the derivation and application of a real-time tool wear sensor in EDM, CIRP Annals-Manufacturing Technology, v35, n1, pp. 111-116.

[3] Snoyes, R., Dauw, D. and Jennes, M. (1982), Survey of EDM adaptive control and detection systems, CIRP Annals-Manufacturing Technology, v31, n2, pp. 483-489.

[4] Yu, Z. Y. and Fujino, M. (1998), Micro-EDM for three-dimensional cavities- development of uniform wear method, CIRP Annals-Manufacturing Technology, v47, n1, pp. 169-172.

[5] Pham, D. T., Ivanov, A., Bigot, S., Popov, K. and Dimov, S. (2007), A study of micro-electro discharge machining electrode wear, Proceedings of the Institution of Mechanical Engineers, Part C-Journal of Mechanical Engineering science, v221, n5, pp. 605-612.

[6] Tsai, Y. and Masuzawa, T. (2004), An index to evaluate the wear resistance of the electrode in micro-EDM, Journal of Materials Processing Technology, v149, n1-3, pp.304-309.

[7] Uhlmann, E. and Rjoehner, M. (2008), Investigations on reduction of tool electrode wear in micro-EDM using novel electrode materials, CIRP Journal of Manufacturing Science and Technology, v1, n2, pp. 92-96.

[8] Bleys, P., Kruth, J. P. and Lauwers, B. (2004), Sensing and compensation of tool wear in milling EDM, Journal of Materials Processing Technology, v149, n1-3, pp. 139-146.

[9] Aligiri, E., Yeo, S. H. and Tan, P. C. (2010), A new tool wear compensation method based on real-time estimation of material removal volume in micro-EDM, Journal of Materials Processing Technology, v210, n15, pp. 2292-2303.

[10] Li, J., Xiao, L., Wang, H., Yu, H. and Yu, Z. (2013), Tool wear compensation in 3D microEDM based on the scanned area, Precision Engineering, v37, n3, pp. 753-757.

[11] Narasimhan, J., Yu, Z. and Rajurkar, K. P. (2005), Tool wear compensation and path generation in micro and macro EDM, Journal of Manufacturing Processes, v7, n1, pp. 75-82.

[12] Rajurkar, K. P. and Yu, Z. Y. (2000), 3D micro-EDM using CAD/CAM, CIRP AnnalsManufacturing Technology, v49, n1, pp. 127-130.

[13] Jung, J. W., Jeong, Y. H., Min, B. and Lee, S. J. (2008), Model-based pulse frequency control for micro-EDM milling using real-time discharge pulse monitoring, Journal of Manufacturing Science and Engineering, v130, n3, pp. 1-11.

[14] Zhang, L., Du, J., Zhuang, X., Wang, Z. and Pei, J. (2015), Geometric prediction of conic tool in micro-EDM milling with fix length compensation using simulation, International Journal of Machine Tools and Manufacture,v89, n1, pp. 86-94.

[15] Wang, J., Yang F., Qian, J. and Reynaerts, D. (2016), Study of alternating current flow in micro-EDM through real-time pulse counting, Journal of Materials Processing Technology, v231, n1, pp. 179-188.

[16] Bissacco, G., Hansen, H. N., Tristo, G. and Valentincic, J. (2011), Feasibility of wear compensation in micro EDM milling based on discharge counting and discharge population characterization, CIRP Annals-Manufacturing Technology, v60, n1, pp. 231-234.

[17] Tristo, G. (2014), Tool wear compensation and energy efficiency in micro milling ElectricalDischarge Machining, $\mathrm{PhD}$ Thesis, University of Padova.

[18] Nirala, C. K. and Saha, P. (2015), Toward development of a new online tool wear compensation strategy in micro-electro-discharge machining drilling, Proceedings of the Institution of Mechanical Engineers, Part B: Journal of Engineering Manufacture, DOI: 10.1177/0954405415578578, 1-12. 
[19] Mahardika, M., Prihandana, G. S. and Mitsui, K. (2012), Precision machining by discharge pulse counting methods in micro EDM processes, Journal of Mechanical Science and Technology, v26, n11, pp.3597-3603.

[20] Mahardika, M. and Mitsui, K. (2008), A new method for monitoring micro-electric discharge machining processes, International Journal of Machine Tools and Manufacture, v48, n3-4, pp. 446-458.

[21] Jung, J. W., Jeong, Y. H., Min, B. and Lee, S. J. (2008), Model-based pulse frequency control for micro-EDM milling using real-time discharge pulse monitoring, Journal of Manufacturing Science and Engineering, v130, n3, pp. 031106: 1-11.

[22] Bissacco, G., Tristo, G., Hansen, H. N. and Valentincic, J. (2013), Reliability of electrode wear compensation based on material removal per discharge in micro EDM milling, CIRP AnnalsManufacturing Technology, v62, n1, pp.179-182. 